\title{
Fuzzy Maximum Torque per Ampere and Maximum Torque per Voltage Control of Interior Permanent Magnet Synchronous Motor Drive
}

\author{
Ming-Shyan Wang, ${ }^{*}$ Min-Fu Hsieh, ${ }^{1}$ Ika Noer Syamsiana, and Wei-Chin Fang \\ Department of Electrical Engineering, Southern Taiwan University of Science and Technology, \\ 1, NanTai Street, Yong Kang District, Tainan City 710, Taiwan (R.O.C.) \\ 'Department of Systems and Naval Mechatronic Engineering, National Cheng Kung University, \\ 1, University Road, East District, Tainan City 701, Taiwan (R.O.C.)
}

(Received September 30, 2016; accepted January 6, 2017)

Keywords: interior permanent magnet synchronous motor, fuzzy logic, maximum torque per ampere (MTPA), maximum torque per voltage (MTPV)

The issue of maximum torque per ampere (MTPA) and maximum torque per voltage (MTPV) control of an interior permanent magnet synchronous motor (IPMSM) is discussed in this paper. A position sensor such as a Hall effect sensor or optical encoder is used in the system. The system will achieve the maximum electromagnetic torque by using MTPA control to drive the IPMSM. As the speed increases to the flux weakening region, MTPV is adopted to give more output torque and promote motor performance. Without dealing with the complex computation of torque control optimization, in this paper we propose fuzzy control to improve the considerable computation burden. The simulation of fuzzy MTPA and MTPV control of IPMSM by Simulink is designed to verify the effectiveness of this computation.

\section{Introduction}

A Hall effect sensor is a transducer that varies its output voltage in response to a magnetic field. It is used in electric motors to detect the position of the permanent magnet (PM). The key factor determining sensitivity of Hall effect sensors is high electron mobility. As a result, the materials gallium arsenide (GaAs), indium arsenide (InAs), indium phosphide (InP), indium antimonide $(\mathrm{InSb})$, and graphene are especially suitable for Hall effect sensors. An optical encoder is an electromechanical device that converts the angular position or motion of a shaft or axle to an analog or digital code. Its disc is made of glass or plastic with transparent and opaque areas. A light source and photo detector array read the optical pattern from the disc's position at any one time.

A permanent magnet motor with an attached position sensor (Hall effect sensor and/or optical encoder) provides more advantages than conventional ac motors, such as simple maintenance, high output torque, high efficiency, high power density, high power factor, low noise, and robustness. ${ }^{(1)}$ It has been widely applied in servo control systems. In addition, applications requiring a wide constant power speed range such as automotive traction, spindle drives, and certain home appliances $^{(2-5)}$ favor an interior permanent magnet synchronous motor (IPMSM) as the machine of choice.

*Corresponding author: e-mail: mswang@stust.edu.tw http://dx.doi.org/10.18494/SAM.2017.1528 
The $d$-axis component of the stator for the IPMSM current has traditionally been maintained at zero in order to make the control easier. However, it is not possible to control the air gap flux, and thus the efficiency of the motor cannot be optimized. Moreover, with zero $d$-axis current control, the reluctance torque of an IPMSM cannot be utilized, which is an advantage of IPMSM as compared with a surface-mounted permanent magnet synchronous motor (PMSM). ${ }^{(1)}$ This feature related to the arrangement of the PMs in the rotor body, which also provides magnetic saliency, makes the direct-axis inductance substantially different from the quadrature-axis inductance, where the $d$-axis is usually selected to be aligned with the PM flux axis. This characteristic is particularly suited for extending the speed operating region by proper field-weakening control techniques. ${ }^{(6)}$

The optimized control of the maximum torque per ampere (MTPA) of IPM motors can be achieved by the proper selection of the current space vector as a function of torque operating condition, often aiming at the maximization of the ratio between the produced torque and the current amplitude. Maximum efficiency control can, in fact, be one of the most attractive criteria, particularly in those applications where machine efficiency is crucial owing to a limited power source (e.g., the battery in automotive applications ${ }^{(5)}$ ). Mathematical and graphical analyses of the constant-torque and constant-current loci provide a means of selecting the optimum current space vector, requiring exact knowledge of motor parameters, particularly direct and quadrature flux characteristics. ${ }^{(1,7,8)}$ A rotor synchronous reference frame is normally adopted in order to ease the computations and, therefore, the implementation of the algorithm in the drive control firmware. Approaches to MTPA tracking in actual drive systems rely on both preconditioned characteristics and real-time estimation and tracking.(6) A novel virtual signal-injection-based control method for MTPA operation of IPMSM drives is also introduced. ${ }^{(9)}$

Control issues on the conventional proportional-integral-derivative (PID) controller, modelreference adaptive controller (MRAC), sliding-mode controller (SMC), and so forth ${ }^{(10,1)}$ have been studied for many years. The designs of these controllers may rely on the exact machine model and accurate model parameters. However, the difficulties of obtaining the exact $d$ - and $q$-axis reactance parameters of the IPMSM will lead to a cumbersome design approach. Moreover, the fixedgain PID controllers are very sensitive to parameter variation and disturbance. ${ }^{(11,12)}$ On the other hand, the designs of intelligent controllers, such as fuzzy logic, neural network, and neurofuzzy controllers, do not need an exact mathematical model of the system. Simplicity and less intensive mathematical design requirements are the main features of intelligent controllers, which are suitable for dealing with the nonlinearities and uncertainties of electric motors. ${ }^{(12-14)}$ Therefore, intelligent controllers demand particular attention for high-performance nonlinear IPMSM drive systems. As a result, an adaptive-network-based fuzzy inference system for the MTPA control for IPMSM drive systems has been proposed. ${ }^{(15)}$ On basis of the injection of proper test signals, ${ }^{(16)}$ the MTPA trajectory is learned and updated in the drive under steady-state conditions to perform a real-time tracking of the MTPA trajectory.

However, the potential reluctance torque of the IPMSM is not fully employed. On the other hand, it is difficult to achieve the MTPA control in a digital signal processor (DSP) owing to the complexity of the MTPA control algorithms. To reduce the amount of calculation, a simplified MTPA method is proposed in a DSP.(6) However, it is inaccurate to compare it with the traditional MTPA control. Therefore, a fuzzy logic controller (FLC), the simplest and better than others in terms of quick response time and insensitivity to parameter and load variations, is the preferred choice $^{(1,6,12,13,17)}$ 
The so-called maximum torque per voltage (MTPV) control denotes that the voltage-limited maximum output current vector control can be used to increase the motor speed further ${ }^{(18)}$ if the center of the voltage limit ellipses of the motor lies inside the current limit circle. By operating the IPMSM along the MTPV trajectory, torque control capability can be extended. If the machine does not operate along MTPV, flux cannot be minimized any further for a constant torque. Consequently, no further flux weakening can be obtained unless the load torque is reduced. Considering the motor parameter variation when the motor operates along the MTPV, a feedforward look-up-table-based method is proposed, ${ }^{(19,20)}$ which indicates the operation of the PMSM along MTPV by controlling both the voltage and current vectors. This method was relatively complicated and still required a look-up table. ${ }^{(21)}$

In this paper, the motor model of IPMSM and the theory of MTPA and MTPV are described in Sect. 2. In Sect. 3, we give the description of the fuzzy logic control system. Simulation results of the proposed IPMSM drive are shown in Sect. 4. Finally, conclusions are offered in Sect. 5.

\section{Modeling the IPMSM}

The voltage equation of the IPMSM is given as ${ }^{(1-5)}$

$$
\left[\begin{array}{c}
v_{u} \\
v_{v} \\
v_{w}
\end{array}\right]=\left[\begin{array}{c}
R_{s} \\
R_{s} \\
R_{s}
\end{array}\right]\left[\begin{array}{c}
i_{u} \\
i_{v} \\
i_{w}
\end{array}\right]\left[\begin{array}{c}
p \lambda_{u} \\
p \lambda_{v} \\
p \lambda_{w}
\end{array}\right],
$$

where $v_{u}, v_{v}$, and $v_{w}$ are the phase voltages; $i_{u}, i_{v}$, and $i_{w}$ are the phase currents; $\lambda_{u}, \lambda_{v}$, and $\lambda_{w}$ are the flux linkages; and $p$ is the differential operator. Assume that the motor provides the balancing condition and has the phase resistance $R_{s}$. Applying the Park transform matrix, we have the new voltage equations in a synchronously rotating ( $d$ - and $q$-axes) frame,

$$
\begin{aligned}
& v_{d}=R_{s} i_{d}+p \lambda_{d}-\omega_{e} \lambda_{q}, \\
& v_{q}=R_{s} i_{q}+p \lambda_{d}-\omega_{e} \lambda_{d},
\end{aligned}
$$

where $\omega_{e}$ is the electric speed, and

$$
\begin{gathered}
\lambda_{d}=L_{d} i_{d}+\lambda_{m}, \\
\lambda_{q}=L_{q} \lambda_{q} .
\end{gathered}
$$

Substituting Eqs.(4) and (5) into Eqs. (2) and (3), we have

$$
\begin{gathered}
v_{d}=R_{s} i_{d}+L_{d} p i_{d}-\omega_{e} L_{q} \lambda_{q}, \\
v_{q}=R_{s} i_{q}+L_{q} p i_{q}+\omega_{e}\left(\lambda_{m}+L_{d} i_{d}\right) .
\end{gathered}
$$

As a result, the electromagnetic torque is expressed by Eq. (8) or (9), 


$$
\begin{gathered}
T_{e}=\frac{3}{2} \frac{P}{2}\left(\lambda_{d} i_{q}-\lambda_{q} i_{d}\right), \\
T_{e}=\frac{3}{2} \frac{P}{2}\left[\lambda_{m} i_{q}+\left(L_{d}-L_{q}\right) i_{q} i_{d}\right],
\end{gathered}
$$

where $P$ is the number of poles, $\lambda_{m}$ is the magnet linkage, $\frac{3}{2} \frac{P}{2} \lambda_{m} i_{q}$ represents the magnetic torque, and $\frac{3}{2} \frac{P}{2}\left(L_{d}-L_{q}\right) i_{q} i_{d}$ is the reluctance torque.

In the real case, the current and voltage are subject to real constraints,

$$
\begin{gathered}
i_{q}^{2}+i_{d}^{2} \leq i_{s}^{2}, \\
v_{q}^{2}+v_{d}^{2} \leq V_{s}^{2} .
\end{gathered}
$$

Equation (10) is shown with a continuous circle in Fig. 1. As the motor runs at a steady state and the voltage drop on resistance is neglected, we have

$$
\begin{gathered}
V_{d}=-\omega_{e} L_{q} i_{q}, \\
V_{q}=\omega_{e} L_{d} i_{d}+\omega_{e} \lambda_{m} .
\end{gathered}
$$

Substituting Eqs. (12) and (13) into Eq. (11) and rearranging it, we obtain the equation of an ellipse,

$$
\left(\frac{V_{s}}{\omega_{e}}\right)^{2}=\left(\lambda_{m}+L_{d} i_{d}\right)^{2}+\left(L_{q} i_{q}\right)^{2}
$$

where the center is at $\left(-\lambda_{m} / L_{d}, 0\right)$, the lengths of the semi major and the semi minor axes are $V_{s} / \omega_{e} L_{d}$ and $V_{s} / \omega_{e} L_{q}$, respectively, for the dashed curves shown in Fig. 1 , and $\omega_{a}<\omega_{b}<\omega_{c}<\omega_{d}$. The overlapped area of the circle and ellipse denotes the operable region of the motor drive system. As the motor speed increases, the lengths of the semi major and the semi minor axes as well as the overlapped area decreases. The point of tangency of the circle and the ellipse denotes the speed at no load under a maximum operable voltage. That is, the motor does not produce torque.

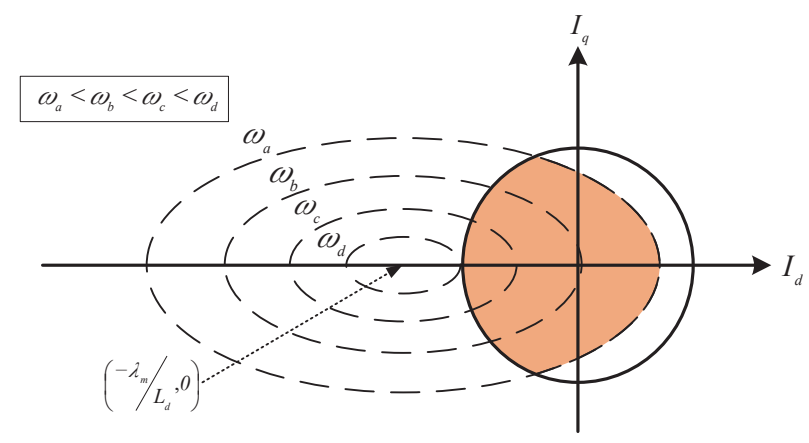

Fig. 1. (Color online) Curves under the drive current and voltage constraints. 
At low speed, the main purpose of motor torque is to accelerate the control system. Under the current constraint of Eq. (10), the stator current can be set only to satisfy the torque requirement. We may find the constant torque curve under some motor speed using Eq. (9) in Fig. 2. For various stator current vectors, $i_{s}^{\prime}, i_{s}^{\prime \prime}$, and $i_{s}^{\prime \prime \prime}$, the motor provides the same torque. As a result, optimal torque control means supplying the same torque using less current to reduce power dissipation or raise efficiency.

From Fig. 3, we can find the relationship between stator currents with the $d$ - and $q$-axis currents,

$$
i_{s}=i_{d}+j i_{q}, i_{d}=i_{s} \cos \beta, i_{q}=i_{s} \sin \beta
$$

Substituting Eq. (15) into Eq. (9), we have a new torque equation,

$$
T_{e}=\frac{3}{2} \frac{P}{2}\left[\lambda_{m} i_{\mathrm{s}} \sin \beta+\frac{1}{2}\left(L_{d}-L_{q}\right) i_{s}^{2} \sin 2 \beta\right] .
$$

It is easy to find that the magnetic torque decreases and the reluctance torque increases as $i_{d}<0$, or the current vector leads to the $q$-axis, shown in Fig. 4. Differentiating Eq. (16) with respect to $\beta$ and setting it to zero, we obtain the angle for the maximum torque output,

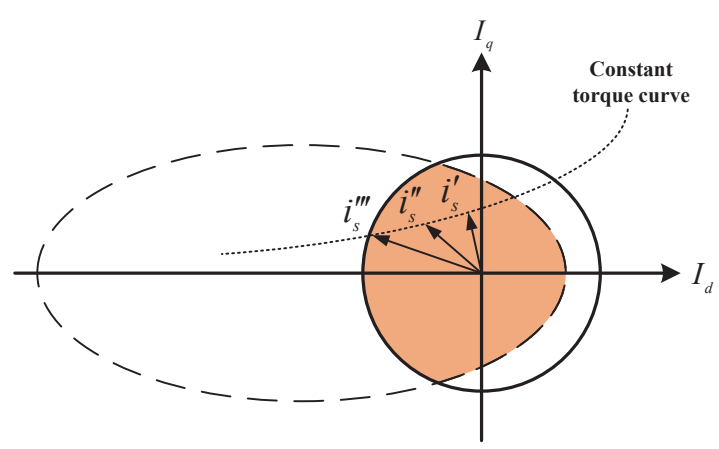

Fig. 2. (Color online) Constant torque curve under the drive current and voltage constraints.

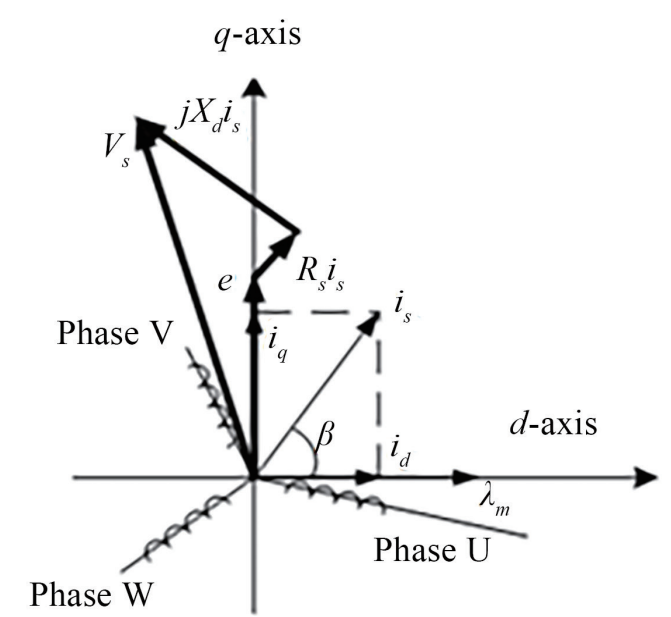

Fig. 3. Diagram of voltage and current vectors.

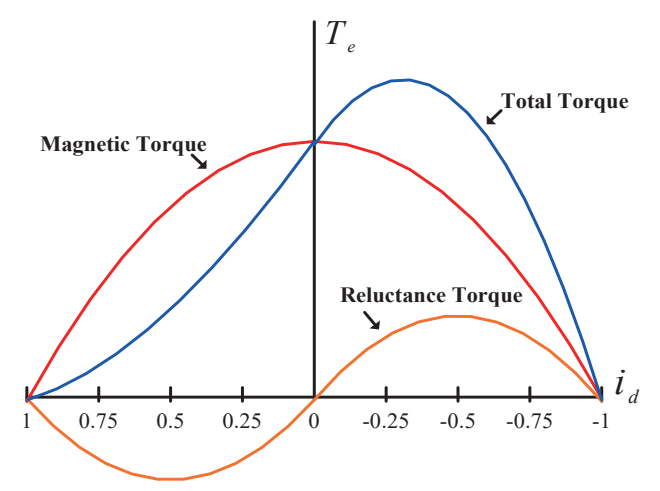

Fig. 4. (Color online) Relationship of torques. 


$$
\beta_{\max }=\sin ^{-1}\left[\frac{-\lambda_{m}+\sqrt{\lambda_{m}+8\left(L_{d}-L_{q}\right)^{2} i_{s}^{2}}}{4\left(L_{d}-L_{q}\right) i_{s}}\right] .
$$

By substituting Eq. (17) into Eq. (15), the relationship of $i_{d}$ to $i_{q}$ is

$$
i_{d}=\frac{\lambda_{m}-\sqrt{\lambda_{m}^{2}+4\left(L_{d}-L_{q}\right)^{2} i_{q}^{2}}}{2\left(L_{d}-L_{q}\right)} .
$$

On the basic of various loads, the curve of the MTPA can be obtained in the field weakening region using Eq. (18), as shown in Fig. 5. The intersection of the MTPA curve, current circle, and voltage ellipse, point A in Fig. 5, denotes the maximum output torque of the motor running at that speed. The analytical development of the MTPA trajectory is based on the simplifying assumption that the motor inductances, namely, the $d$ - and $q$-axis inductances, are constant, i.e., no saturation and crossmagnetization effects are considered. In this case, the direct and quadrature current components of the current space vector are obtained by the intersection between the constant (commanded)-torque locus (a hyperbola in the $d q$-current plane) and the constant-current locus (a circle in the $d q$-current plane), with the constraint of minimum length of the current space vector (i.e., the constant-current locus is tangent to the torque locus).

Controlling the current vector so that the torque per flux linkage becomes maximum is called the MTPV control. If the characteristic current $\left|\lambda_{m} / L_{d}\right|$ is less than the rated current of the machine, the torque controllability in the flux-weakening range can be extended by using MTPV control. The relationship between $i_{d}$ and $i_{q}$ for MTPV is given in Eq. (19),

$$
i_{d}=\frac{\lambda_{m}-\lambda_{d}}{L_{d}}, i_{q}=\frac{\sqrt{\lambda_{s}^{2}-\lambda_{d}^{2}}}{L_{q}} .
$$

From Eq. (14), we have Eqs. (20) and (21),

$$
V_{s}=\omega_{e}{ }^{2}\left(L_{q} i_{q}\right)^{2}+\omega_{e}{ }^{2}\left(L_{q} i_{q}+\lambda_{m}\right)^{2},
$$

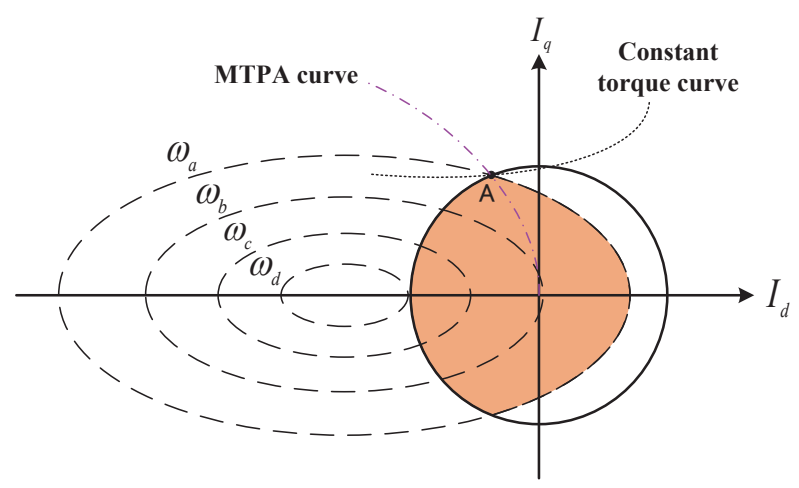

Fig. 5. (Color online) MTPA curve. 


$$
\lambda_{s}=\sqrt{\lambda_{d}^{2}+\lambda_{q}^{2}}=\frac{V_{s}}{\omega_{e}}
$$

By substituting Eqs. (20) and (21) into Eq. (8), the new equation for torque is

$$
T_{e}=\left(\frac{3 P}{4}\right)\left[\lambda_{d}\left(\frac{\sqrt{\lambda_{s}^{2}-\lambda_{d}^{2}}}{L_{q}}\right)+\sqrt{\lambda_{s}^{2}-\lambda_{d}^{2}}\left(\frac{\lambda_{m}-\lambda_{d}}{L_{d}}\right)\right] .
$$
Differentiating Eq. (22) with respect to $\lambda_{d}$ and setting it to zero, that is, $\frac{\partial T_{e}}{\partial \lambda_{d}}=0$, we have the $d$-axis
flux and current for MTPV,

$$
\begin{gathered}
\lambda_{d, \max }=\frac{-L_{q} \lambda_{m}+\sqrt{\left(L_{q} \lambda_{m}\right)^{2}+8\left(L_{d}-L_{q}\right)^{2}\left(\frac{V_{s}}{\omega_{e}}\right)^{2}}}{4\left(L_{d}-L_{q}\right)}, \\
i_{d, \max }=-\frac{\lambda_{m}-\lambda_{d, \max }}{L_{d}} .
\end{gathered}
$$

Based on Eqs. (23) and (24), the MTPV curve can be shown in Fig. 6.

\section{FLC Systems}

A FLC system basically consists of blocks of the knowledge base (data and rule bases), the inference engine, the fuzzification interface, and the defuzzification interface, as shown in Fig. 7. The inputs and outputs are crisp. The fuzzification block converts the crisp inputs to fuzzy sets, and the defuzzification block converts these fuzzy conclusions back into the crisp outputs to ensure the requested performance. Essentially, the fuzzy controller can be viewed as an artificial decision maker based on the experts' experience that operates in a closed-loop system in real time.

In order to optimize the MTPA by fuzzy logic, the $q$-axis feedback current $i_{q}$ and the motor speed $\omega_{r}$ are used as the inputs, and the $d$-axis current $i_{d}^{*}$ command is used as the output. For

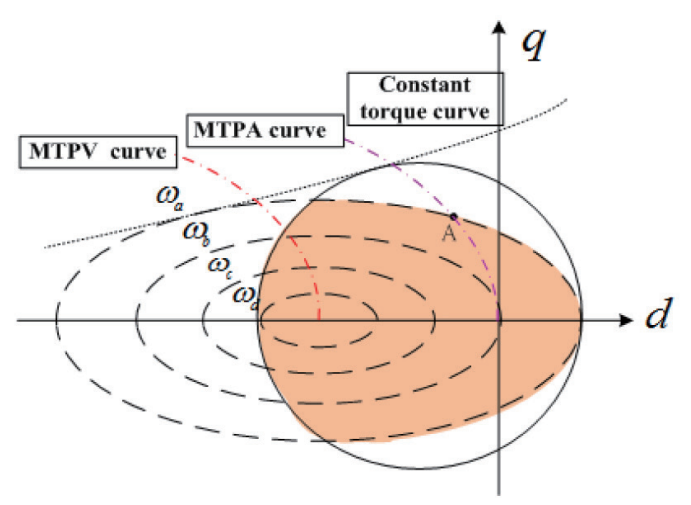

Fig. 6. (Color online) MTPA, MTPV, and constant torque curves. 
simplicity, the linguistic values Z, S, M, B, and VB standing for zero, small, medium, big, and very big, respectively, are adopted. The membership functions of these input and output fuzzy variables are shown in Fig. 8. The triangular form of the membership functions is easy to calculate. It satisfies the purpose of fuzzy MTPA to reduce the computation burden. In addition, the value of the horizontal axis is normalized for easy computation.

There are 25 rules given as follows:

Rule (1): if $i_{q}$ is $\mathrm{Z}$ and $\omega_{r}$ is $\mathrm{Z}$ then $i_{d}^{*}$ is $\mathrm{S}$

Rule (2): if $i_{q}$ is $\mathrm{Z}$ and $\omega_{r}$ is $\mathrm{S}$ then $i_{d}{ }^{*}$ is $\mathrm{M}$

Rule (3): if $i_{q}$ is $\mathrm{Z}$ and $\omega_{r}$ is $\mathrm{M}$ then $i_{d}{ }^{*}$ is $\mathrm{B}$

Rule (25): if $i_{q}$ is $\mathrm{VB}$ and $\omega_{r}$ is $\mathrm{VB}$ then $i_{d}^{*}$ is $\mathrm{B}$

Table 1 lists the rule bases for deriving the output fuzzy variable. The min-min-max inference and mean of height method, expressed by Eq. (22), are used in the FLC system,

$$
\hat{y}=\frac{\sum_{i=1}^{n} f_{i} \times g_{i}}{\sum_{i=1}^{n} f_{i}}
$$

where $g_{i}$ is the center of the $i$ th fuzzy set, $f_{i}$ is its height, and $\hat{y}$ is the center average.

\section{Simulation Results}

Figure 9 shows the block diagram of the proposed control system that includes the test IPMSM, its drive, and the servo motor for loading. The parameters of IPMSM are listed in Table 2. The block diagram of the IPMSM drive system by Simulink is shown in Fig. 10, where the red block

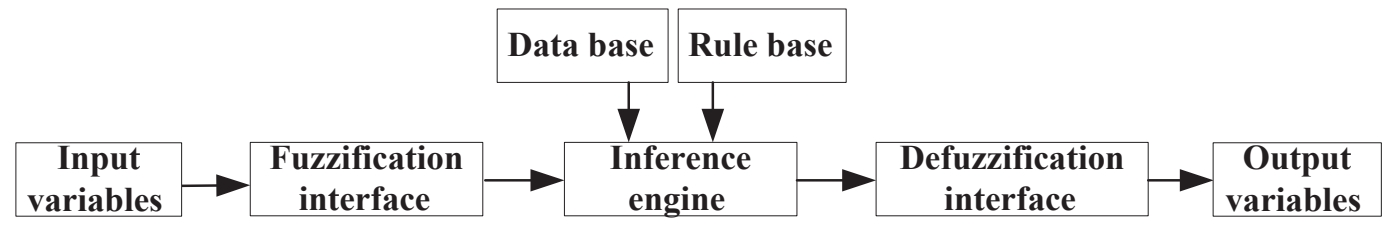

Fig. 7. Basic architecture of a fuzzy control system.

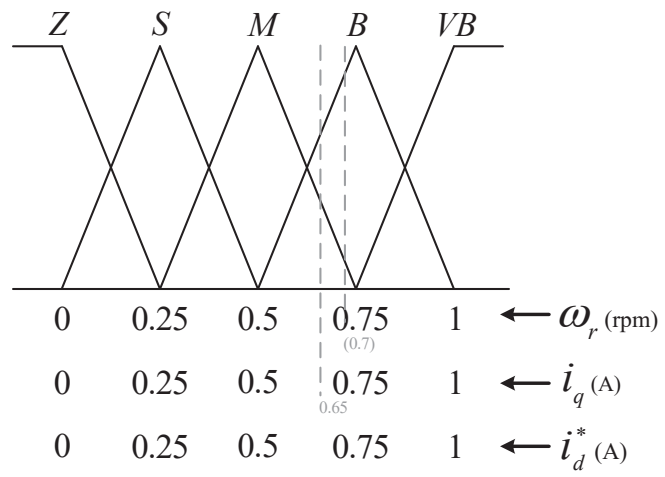

Fig. 8. Membership functions of fuzzy variables.
Table 1

Rule table.

\begin{tabular}{cccccc}
\hline$\omega_{\wedge} i_{q}$ & $\boldsymbol{O}$ & $\boldsymbol{S}$ & $\boldsymbol{M}$ & $\boldsymbol{B}$ & $\boldsymbol{V B}$ \\
\hline $\boldsymbol{O}$ & $S$ & $M$ & $B$ & $B$ & $V B$ \\
$\boldsymbol{S}$ & $S$ & $M$ & $M$ & $V B$ & $V B$ \\
$\boldsymbol{M}$ & $S$ & $S$ & $M$ & $B$ & $V B$ \\
$\boldsymbol{B}$ & $O$ & $S$ & $M$ & $B$ & $V B$ \\
$\boldsymbol{V B}$ & $O$ & $S$ & $M$ & $B$ & $B$ \\
\hline
\end{tabular}




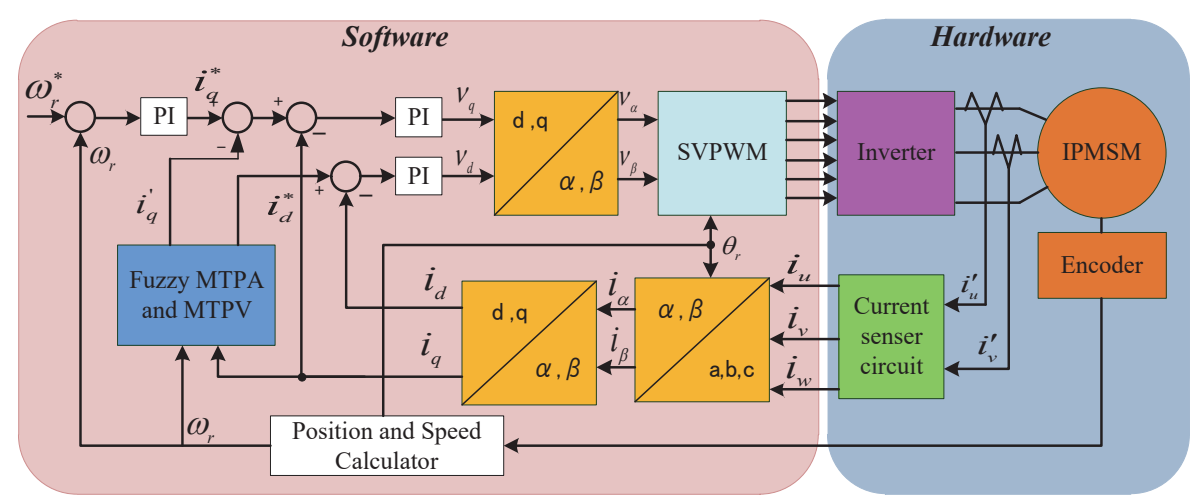

Fig. 9. (Color online) Block diagram of the controlled system.

Table 2

Motor parameters.

\begin{tabular}{lccc}
\hline Number of poles & 4 poles & $q$-axis inductance & $88.99 \mu \mathrm{H}$ \\
\hline Rated voltage & $48 \mathrm{~V}$ & Rated speed & $2000 \mathrm{rpm}$ \\
Rated current & $70 \mathrm{~A}$ & Rated torque & $7 \mathrm{Nm}$ \\
Resistance & $0.00623 \Omega$ & Flux linkage & $0.014986 \mathrm{~Wb}$ \\
Inertia & $0.0002339 \mathrm{~kg} \cdot \mathrm{m}^{2}$ & Viscous coefficient & $8.35578 \mathrm{e}-008 \mathrm{~nm} \cdot \mathrm{s} / \mathrm{rad}$ \\
$d$-axis inductance & $22.54 \mu \mathrm{H}$ & Incremental encoder & $2500 \mathrm{ppr}$ \\
\hline
\end{tabular}

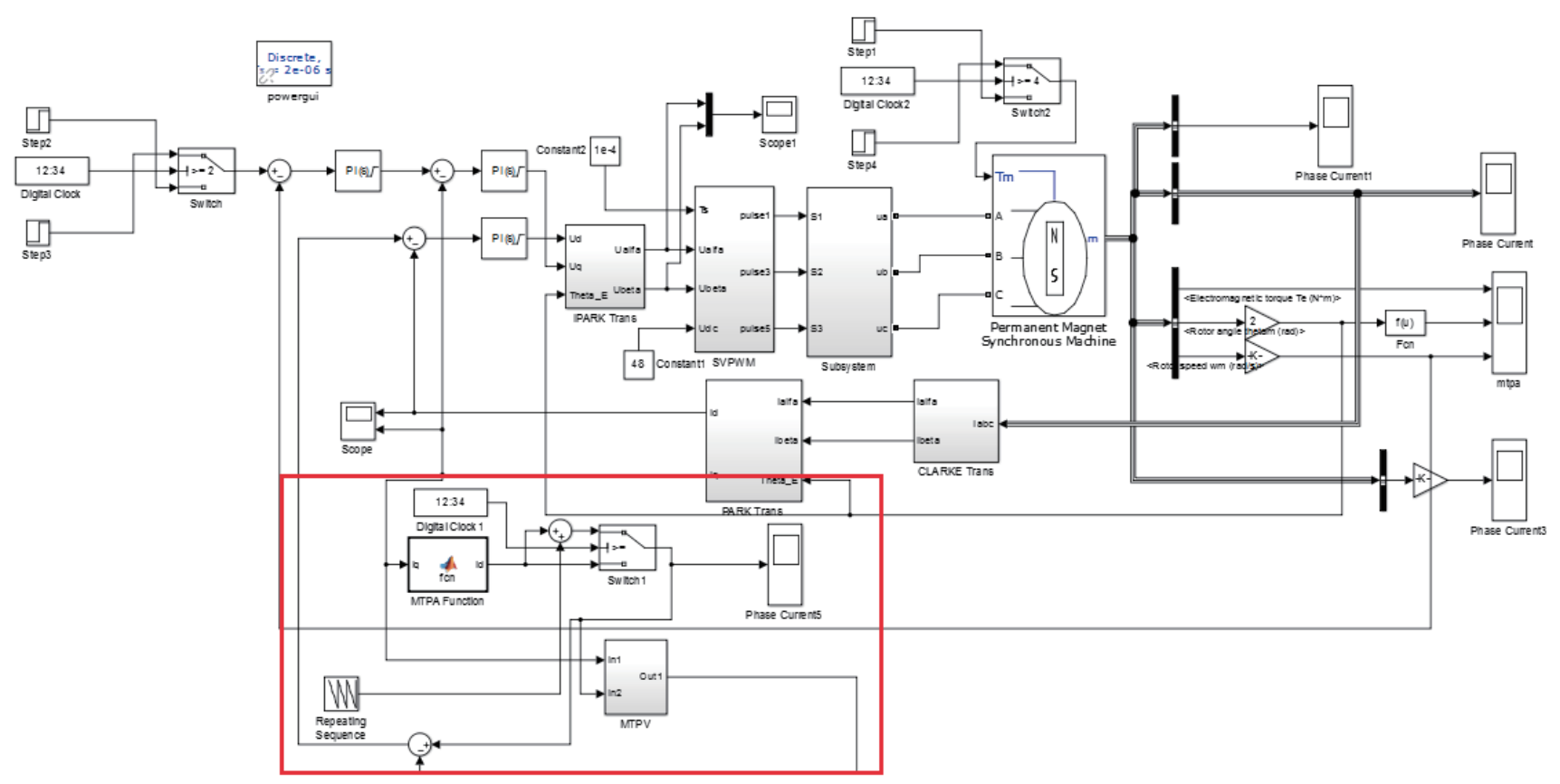

Fig. 10. (Color online) Block diagram of IPMSM drive system by Simulink.

stands for fuzzy MTPA and MTPV control. The simulation focuses on the constant-power region and constant torque region. 
Figure 11 shows the simulation results of phase $U$ current with the following conditions: motor speed of $300 \mathrm{rpm}$, fixed torque angle (zero $d$-axis current) command, and loads of $0.5,2,4$, and 5 Nm. Figure 12 shows the simulation results of phase $U$ current by fuzzy MTPA under the same conditions as Fig. 10. Since zero, the $d$-axis current command, is considered, there is no reluctance torque generated. We summarize Figs. 11 and 12 in Fig. 13. It is easily found that the larger the

(a)

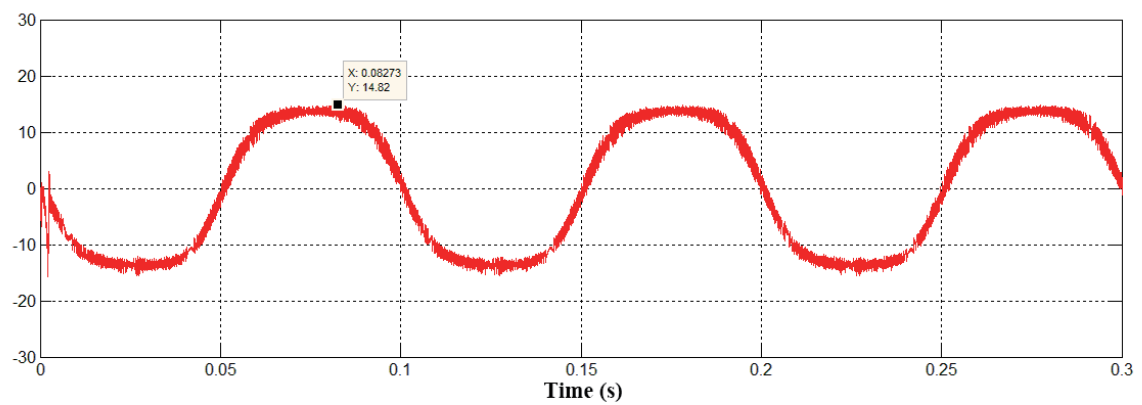

(b)

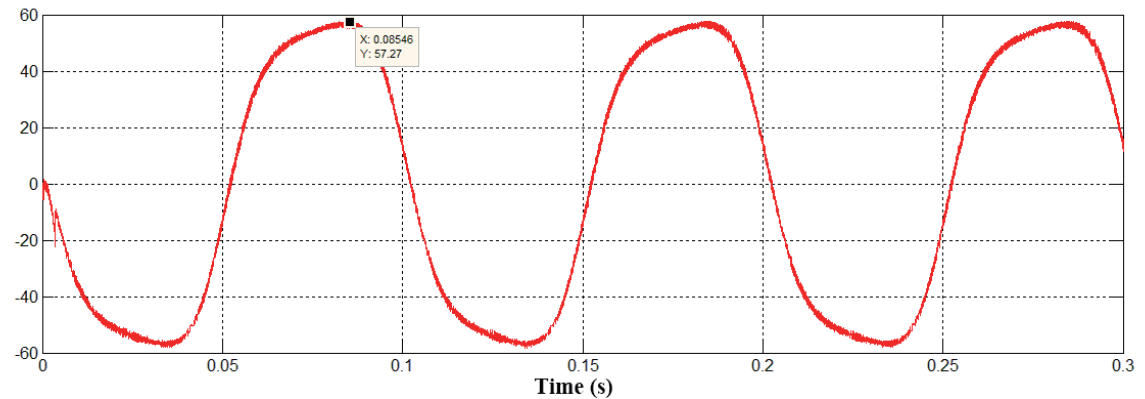

(c)

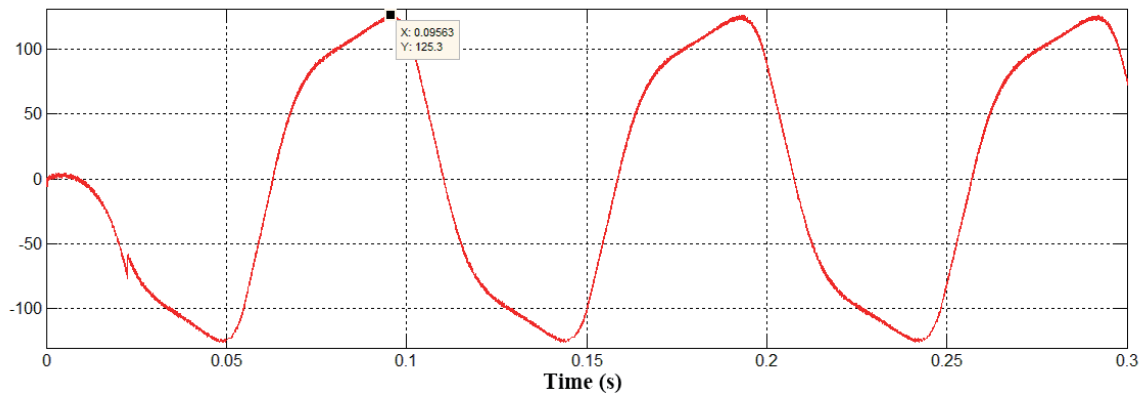

(d)

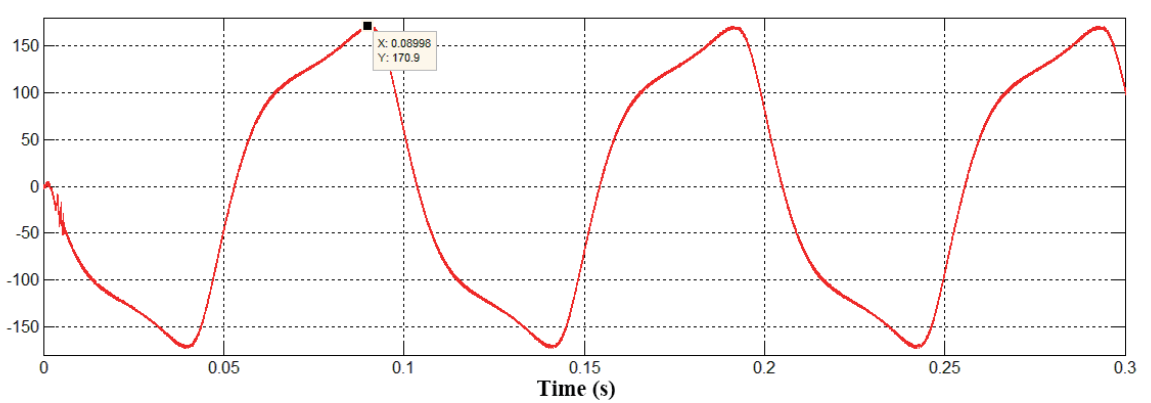

Fig. 11. (Color online) Current waveform of phase U with MTPA (a) at $0.5 \mathrm{Nm}$ load with amplitude of $14.82 \mathrm{~A}$, (b) at $2 \mathrm{Nm}$ load with amplitude of $57.27 \mathrm{~A}$, (c) at $4 \mathrm{Nm}$ load with amplitude of $125.3 \mathrm{~A}$, and (d) at $5 \mathrm{Nm}$ load with amplitude of 170.9 A. 
(a)

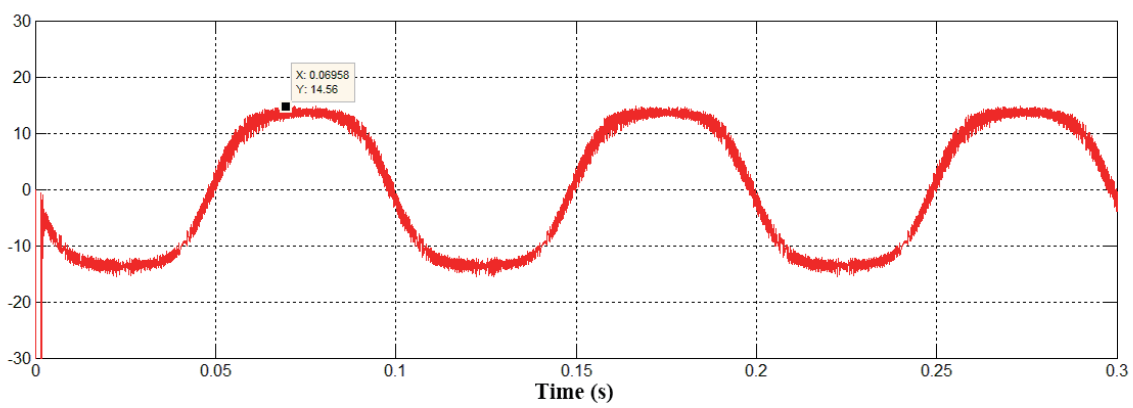

(b)

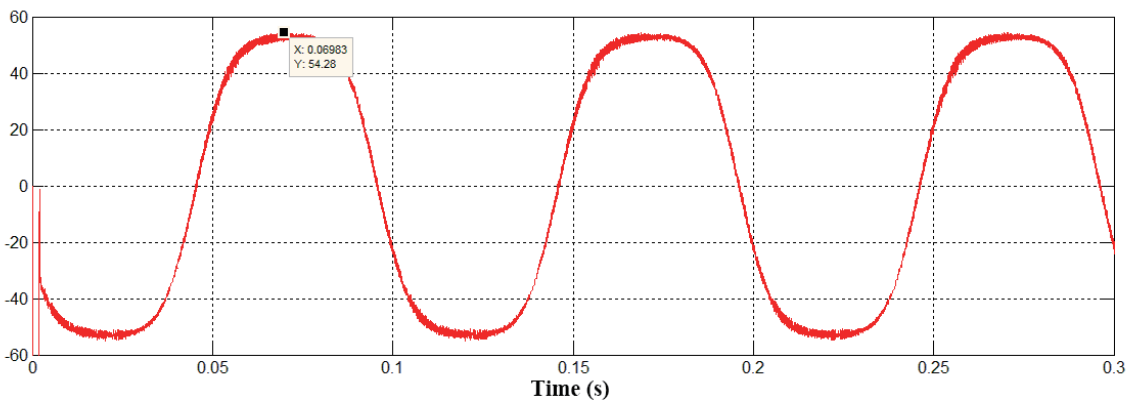

(c)

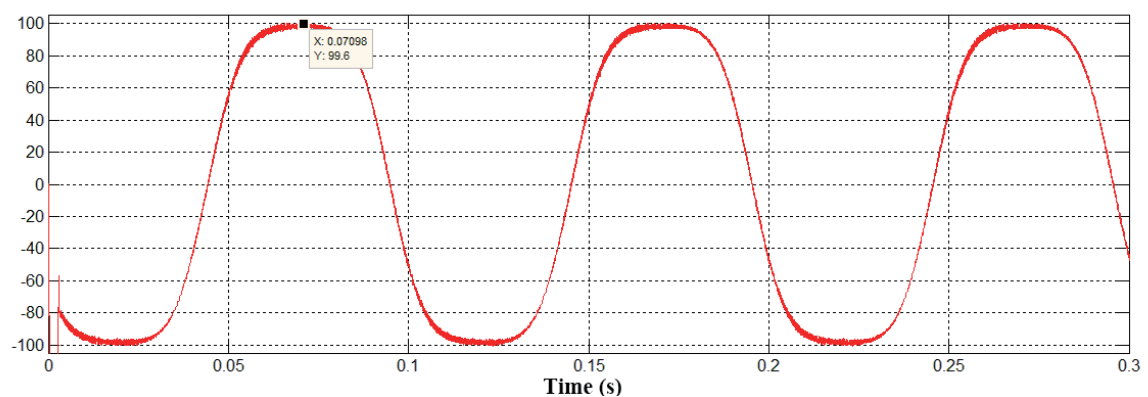

(d)

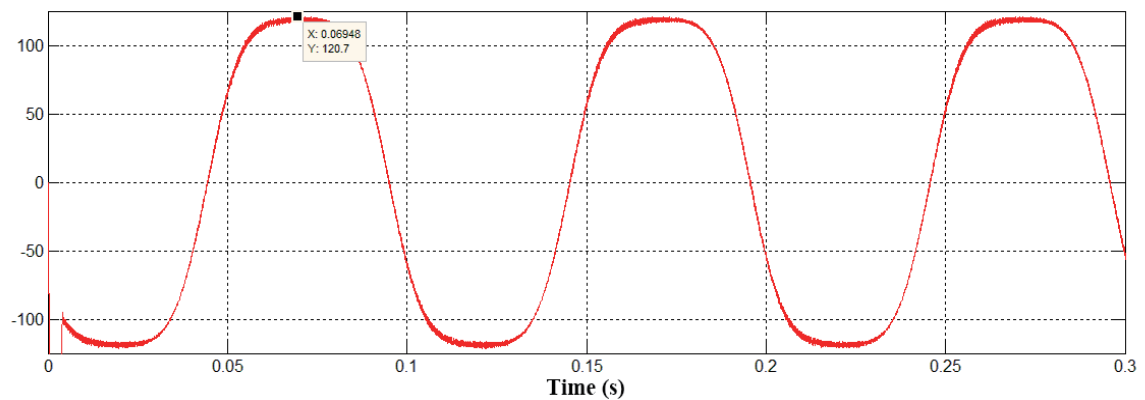

Fig. 12. (Color online) Current waveform of phase $\mathrm{U}$ with fixed torque angle, (a) at $0.5 \mathrm{Nm}$ load with amplitude of $14.56 \mathrm{~A}$, (b) at $2 \mathrm{Nm}$ load with amplitude of $54.28 \mathrm{~A}$, (c) at $4 \mathrm{Nm}$ load with amplitude of $99.6 \mathrm{~A}$, and (d) at 5 Nm load with amplitude of $120.7 \mathrm{~A}$.

$q$-axis current, the better the performance by fuzzy MTPA at the constant-torque region. In a similar way, we can obtain the speed responses under the same conditions as Figs. 10 and 11, and then depict the fuzzy MTPV control in Fig. 14. The motor speed by fuzzy MTPV control is higher than that by conventional control in the constant-power region. 


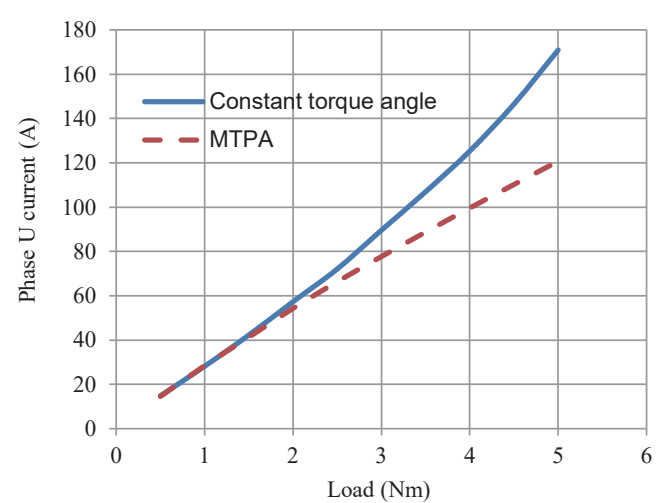

Fig. 13. (Color online) Curves of load vs current at $300 \mathrm{rpm}$ by fixed torque angle method and fuzzy MTPA control.

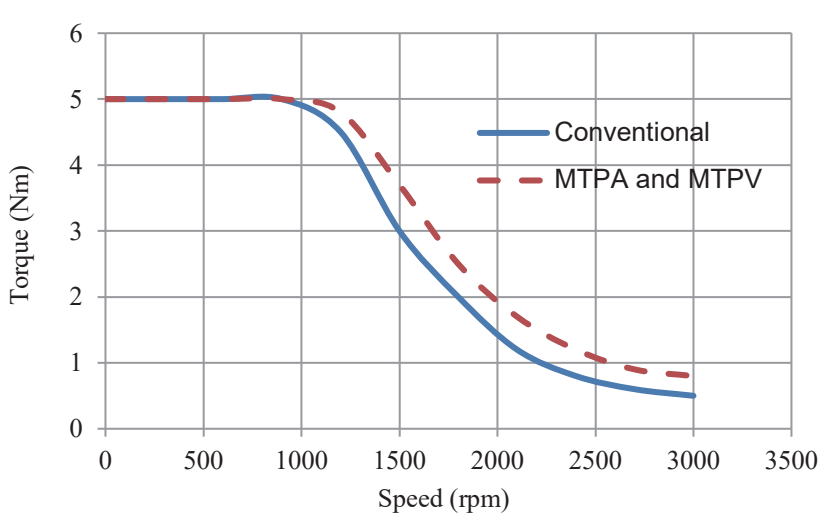

Fig. 14. (Color online) $T-N$ curves by fixed torque angle method and fuzzy MTPA/MTPV control.

\section{Conclusions}

In this paper, we propose torque control with a maximum torque per ampere and a maximum torque per voltage technique based on fuzzy theory and without dealing with the complex computation of torque control optimization for the IPMSM. From the simulation results shown in Figs. 13 and 14, the effectiveness of the proposed fuzzy MTPA/MTPV control is verified.

\section{Acknowledgements}

The authors would like to express their appreciation to the Ministry of Science and Technology, Taiwan under contract No. 104-2221-E-218-025 for financial support.

\section{References}

1 M. N. Uddin and J. Khastoo: IEEE Trans. Ind. Appl. 50 (2014) 4251.

P. Lazari, J. Wang, and L. Chen: IEEE Trans. Ind. Appl. 50 (2014) 3203.

C. T. Pan and S. M. Sue: IEEE Trans. Energy Convers. 20 (2005) 359.

4 M. N. Uddin, T. S. Radwan, and M. A. Rahman: IEEE Trans. Energy Convers. 17 (2002) 79.

5 S. Bolognani, S. Calligaro, and R. Petrella: IEEE J. Emerging Sel. Top. Power Electron. 2 (2014) 236.

6 M. N. Uddin and R. S. Rebeiro: IEEE Trans. Ind. Appl. 47 (2011) 1043.

7 T. Inoue, Y. Inoue, S. Morimoto, and M. Sanada: IEEE Trans. Ind. Appl. 52 (2016) 2360.

8 T. Sun, J. Wang, and M. Koc: IEEE Trans. Ind. Electronics 63 (2016) 4773.

9 T. Sun, J. Wang, and X. Chen: IEEE Trans. Power Electronics 30 (2015) 5036.

10 M. M. I. Chy and M. N. Uddin: IEEE Trans. Ind. Appl. 45 (2009) 1106.

11 Z. Ibrahim and E. Levi: IEEE Trans. Ind. Appl. 38 (2002) 1210.

12 A. Rubaai, D. Rickattes, and M. D. Kankam: IEEE Trans. Ind. Appl. 38 (2002) 441.

13 M. N. Uddin and M. A. Rahman: IEEE Trans. Ind. Electron. 54 (2007) 190.

14 H. Kim, J. Hartwig, and R. D. Lorenz: Proc. Power Electronics Specialists Conference (2002) p. 815.

15 Y. A. R. I. Mohamed and T. K. Lee: IEEE Trans. Energy Convers. 21 (2006) 636.

16 S. Bolognani, R. Petrella, A. Prearo, and L. Sgarbossa: IEEE Trans. Ind. Appl. 47 (2011) 105

17 M.-S. Wang, M.-F. Hsieh, Y.-S. Kung, and G. T. Lin: Microsyst. Technol. 22 (2016) 1668.

18 S. Morimoto, Y. Takeda, T. Hirasa, and K. Taniguchi: IEEE Trans. Ind. Appl. 26 (1990) 866.

19 C. Bing and T. R. Tesch: IEEE Trans. Ind. Electron. 57 (2010) 969.

20 G. Gallegos-Lopez, F. S. Gunawan, and J. E. Walters: IEEE Trans. Ind. Appl. 41 (2005) 1020.

21 S. Ekanayake, R. Dutta, M. F. Rahman, and D. Xiao: Proc. IECON 2015-41st Annual Conference of the IEEE Industrial Electronics Society (2015) p. 4802. 